\title{
Fungus-mediated biological synthesis of gold nanoparticles: potential in detection of liver cancer
}

This article was published in the following Dove Press journal:

International Journal of Nanomedicine

I| October 20 | |

Number of times this article has been viewed

\author{
Arun Chauhan' \\ Swaleha Zubair ${ }^{2}$ \\ Saba Tufail' \\ Asif Sherwani' \\ Mohammad Sajid' \\ Suri C Raman ${ }^{3}$ \\ Amir Azam ${ }^{4}$ \\ Mohammad Owais' \\ 'Interdisciplinary Biotechnology \\ Unit, ${ }^{2}$ Women's College, Aligarh \\ Muslim University, Aligarh, ${ }^{3}$ Institute \\ of Microbial Technology, Chandigarh, \\ ${ }^{4}$ Centre of Excellence in Material \\ Sciences, Department of Applied \\ Physics, Aligarh Muslim University, \\ Aligarh, India
}

Background: Nanomaterials are considered to be the pre-eminent component of the rapidly advancing field of nanotechnology. However, developments in the biologically inspired synthesis of nanoparticles are still in their infancy and consequently attracting the attention of material scientists throughout the world. Keeping in mind the fact that microorganism-assisted synthesis of nanoparticles is a safe and economically viable prospect, in the current study we report Candida albicans-mediated biological synthesis of gold nanoparticles.

Methods and results: Transmission electron microscopy, atomic force microscopy, and various spectrophotometric analyses were performed to characterize the gold nanoparticles. The morphology of the synthesized gold particles depended on the abundance of C. albicans cytosolic extract. Transmission electron microscopy, nanophox particle analysis, and atomic force microscopy revealed the size of spherical gold nanoparticles to be in the range of 20-40 nm and nonspherical gold particles were found to be $60-80 \mathrm{~nm}$. We also evaluated the potential of biogenic gold nanoparticles to probe liver cancer cells by conjugating them with liver cancer cell surface-specific antibodies. The antibody-conjugated gold particles were found to bind specifically to the surface antigens of the cancer cells.

Conclusion: The antibody-conjugated gold particles synthesized in this study could successfully differentiate normal cell populations from cancerous cells.

Keywords: gold nanoparticles, Candida albicans, biomimetic synthesis, cancer cell diagnosis, antiliver cell antibody

\section{Introduction}

Nanosized particles have attracted worldwide attention in recent times due to their unusual optical, chemical, photoelectrochemical, and electronic properties. ${ }^{1-4}$ These particles have had a wide application in a range of areas, including catalysis, optics, mechanics, magnetics, energetics, and biomedical sciences. ${ }^{5}$ It seems that nanoscience might take center stage in many key future technologies because of recent efforts in fabricating these nanosized structures into predefined superstructures. In order to meet the wide scope of nanomaterials, an overwhelming number of protocols have been exploited for their synthesis, but unfortunately, most of them are capital-intensive, inefficient in material and energy use, and often pose health hazards as a consequence of usage of toxic chemicals. Therefore, there is a need to develop safe, reliable, nontoxic, cost effective, clean, and ecofriendly methods for the preparation of nanoparticles. As a result, nanomaterial synthesis mediated by biological systems (bacteria, fungi, and plant extracts) has attracted scientific interest across the globe.
Correspondence: Mohammad Owais Interdisciplinary Biotechnology Unit, Aligarh Muslim University, Aligarh 202002, India

$\mathrm{Tel}+9 \mid 057$ I 2720388

Fax +9| $057|272| 776$

Email owais_lakhnawi@yahoo.com 
Both intracellular and extracellular production of nanoparticles from inorganic materials is a well known attribute of many microorganisms. ${ }^{6-9}$ For example, unicellular organisms such as magnetotactic bacteria produce magnetite nanoparticles, ${ }^{10-12}$ and, similarly, diatoms synthesize siliceous materials. ${ }^{13-15}$ Although microorganisms like bacteria and fungi have been employed in the remediation of toxic metals, ${ }^{16,17}$ their exploitation as possible ecofriendly nanofactories has occurred only recently. ${ }^{18,19}$ Nanocrystals of gold, silver, and their alloys have been synthesized with the assistance of various bacteria as well as some fungi. ${ }^{20,21}$ Biosynthesis of nanoparticles is a kind of bottom-up approach, whereby the main reaction occurring involves reduction/ oxidation of substrates, giving rise to colloidal structures. Microbial enzymes or plant phytochemicals with antioxidant or reducing properties are usually responsible for reduction of metal compounds into their respective nanoparticles. ${ }^{22}$ Bioreduced metal atoms undergo nucleation with subsequent growth, leading to the generation of nanostructures.

Here we report synthesis of gold nanoparticles by the reaction of chloroaurate ions with a cytosolic extract of Candida albicans. The shape of the gold nanoparticles was found to be regulated by changing the concentration of cytosolic extract in the reaction mixture. The prepared gold nanoparticles were characterized using ultraviolet-visible spectroscopy, Fourier transform infrared spectroscopy, transmission electron microscopy, atomic force microscopy, and nanophox particle analysis.

Several studies of nanoparticle bioconjugation have been reported in recent years, including synthesis of gold nanoparticles directly conjugated with bovine serum albumin. ${ }^{23,24}$ The unique optical and electronic properties of gold nanoparticles make them ideal candidates for cell targeting and also as efficient tools for bioassays. ${ }^{25}$ On this basis, we sought to develop a fluorescence-based biosensor using liver cancer cell surface-specific (LCCS) antibody-conjugated gold colloids to probe cancer cells specifically in a mixed cell population.

\section{Materials and methods}

\section{Chemicals and reagents}

All the chemicals and reagents used were of the highest purity available. Chloroauric acid $\left(\mathrm{HAuCl}_{4}\right)$, diethyl nitrosamine, horseradish peroxidase-conjugated antirabbit $\operatorname{IgG}, 3,3$ 'diaminobenzidine tetrahydrochloride, and Tween 20 were purchased from Sigma-Aldrich Chemicals (St Louis, MO) and used as received. Kits to estimate liver enzymes were obtained from SPAN Diagnostics (Gujarat, India).
Thioglycolate media and a protein A column were procured from Himedia Laboratories Pvt Ltd (Mumbai, India) and Bangalore Genei (India) Pvt Ltd (Bangalore, India), respectively. Sterile filters of $0.22 \mu \mathrm{m}$ in size were purchased from Millipore (India) Pvt Ltd (Bengaluru, India). HeLa cells were obtained from the American Type Culture Collection (Manassas, VA) and 3-(4,5-dimethythiazol-2-yl)-2,5diphenyl tetrazolium bromide (MTT) from Sigma-Aldrich Chemicals.

\section{Isolation of cytosolic extract from C. albicans}

C. albicans was cultured on YEDP agar plates. The cells were harvested after 24 hours and homogenized in chilled lysis buffer supplemented with a protease inhibitor cocktail, ie, $2 \%$ Triton X-100 (w/v), 1\% sodium dodecyl sulfate, $100 \mathrm{mM}$ Tris- $\mathrm{HCl}$ (pH 8.0), $100 \mathrm{mM} \mathrm{NaCl}, 1 \mathrm{mM}$ ethylenediamine tetra-acetic acid ( $\mathrm{pH} \mathrm{8.0)}$, and $1 \mathrm{mM}$ phenylmethylsulfonyl fluoride. The homogenate was sonicated for 45 minutes at $4^{\circ} \mathrm{C}$ using a bath sonicator. Subsequently, the homogenate was vortexed for 1 hour with intermittent cooling at $4{ }^{\circ} \mathrm{C}$. The preparation was pelleted at $2000 \mathrm{~g}$ for 15 minutes, and the supernatant was collected and kept at $-20^{\circ} \mathrm{C}$ until further use.

\section{Synthesis of gold nanoparticles using C. albicans cytosolic extract}

Different volumes $(1-5 \mathrm{~mL})$ of cytosolic extract were added to $5 \mathrm{~mL}$ solution of $10^{-3} \mathrm{M}$ aqueous $\mathrm{HAuCl}_{4}$, and the volume was made up to $10 \mathrm{~mL}$ by adding the appropriate amount of deionized water. The mixture was incubated for 24 hours to complete the reaction. The synthesized gold nanoparticle product was characterized by ultraviolet-visible spectroscopy, transmission electron microscopy, atomic force microscopy, and Fourier transform infrared analyses.

\section{Ultraviolet-visible and fluorescence spectroscopy}

To characterize the synthesized gold nanoparticles, they were scanned in the 300-1000 nm wavelength range using a double beam spectrophotometer (Perkin Elmer, Boston, MA). Fluorescence spectra were recorded with a Hitachi F-4500X fluorescence spectrometer (Hitachi, Tokyo, Japan) controlled by a personal computer data processing unit. The excitation at $488 \mathrm{~nm}$ and the emission spectra from $505 \mathrm{~nm}$ to $550 \mathrm{~nm}$ were collected. All excitation and emission slits were set at $5 \mathrm{~nm}$. 


\section{Transmission electron microscopy}

The size, shape, and morphology of the synthesized gold nanoparticles were analyzed using a transmission electron microscope (1200 EX, JOEL Inc, Peabody, MA) following a method described elsewhere. ${ }^{26}$ Samples were prepared by putting a drop of the gold particles on a negative carboncoated copper grid and dried in air before being transferred to the transmission electron microscope.

\section{Fourier transform infrared spectroscopy}

Fourier transform infrared spectroscopic measurement of the gold nanoparticles was carried out by depositing purified particles on Si (111) wafers with simple dropcoating and subjecting them to analysis (6700 spectrum; Thermo Nicolet, Madison, WI) in a diffuse reflectance mode at a resolution of $4 \mathrm{~cm}^{-1}$.

\section{Atomic force microscopy}

Samples of the biogenic gold nanoparticles generated using C. albicans cytosolic extract were centrifuged and redispersed in deionized water. Samples were passed through a $0.22 \mu \mathrm{m}$ filter, and an aliquot of reaction mixture was placed on a Si disc and dried in a nitrogen atmosphere. Finally, the samples were analyzed using a contact mode atomic force microscope (Perkin Elmer).

\section{Animals}

Female BALB/c mice weighing $18 \pm 2 \mathrm{~g}$ and aged 8-10 weeks were obtained from the animal house facility of the Institute of Microbial Technology and used for induction of liver cancer and generation of the cancer cell-specific antibody. The animals were kept on a standard pellet diet and had access to water ad libitum. The animals were checked daily for mortality and morbidity prior to commencement of the study, and only healthy animals were included in the experiment. The techniques used for bleeding, injection, and sacrifice were performed strictly in accordance with mandates approved by the Government of India animal ethics committee for the control and supervision of experiments on animals.

\section{Gold nanoparticle uptake by macrophages}

Macrophages $\left(1 \times 10^{6}\right)$ were isolated from the intraperitoneal cavity of thioglycolate-primed BALB/c mice. The macrophages were incubated with $1 \mu \mathrm{M}$ of gold nanoparticles conjugated with LCCS antibodies for $1-2$ hours at $37^{\circ} \mathrm{C}$ in a humidified atmosphere of $5 \% \mathrm{CO}_{2}$ and then centrifuged at $1500 \mathrm{~g}$ for 4 minutes. The cells were fixed on a slide for observation using a fluorescent microscope (Axio, HBU 50/ AC; Zeiss, Gottingen, Germany).

\section{Induction of liver cancer by diethyl nitrosamine}

Liver cancer in BALB/c mice was induced following a method described elsewhere. ${ }^{27}$ Establishment of liver cancer was confirmed by estimation of liver enzymes (alkaline phosphatase, aspartate transaminase, and gamma glutamyltransferase), and histopathological studies were performed after 1 month of diethyl nitrosamine administration.

\section{Isolation of tumor cell proteins and development of LCCS antibodies}

Tumor cells were isolated from the mice following a standard protocol. ${ }^{28} \mathrm{~A}$ tumor cell lysate was prepared according to a previously published procedure. ${ }^{28}$ The protein content of each sample was estimated using the conventional method with bovine serum albumin as a standard. ${ }^{29}$ The animals were immunized with a total of three doses of antigen $(100 \mu \mathrm{g}$ per animal on days 0,14 , and 21 ). On day 25 , the animals were bled and serum was isolated for antibody collection. A protein A column was used to purify the antibody. The eluted antibodies were precleared by incubation with cell lysate prepared from normal healthy liver cells. For this, the mixture was incubated for 6 hours followed by centrifugation at $3000 \mathrm{~g}$ to remove the agglutinated mass, and the supernatant was further processed using the following method to obtain the LCCS antibodies.

\section{Purification of LCCS antibodies}

Tumor cells were isolated from the mice following a standard protocol..$^{28}$ For development of the LCCS antibodies, we used a whole cell lysate that induced indiscriminate production of antibodies specific for the cytosol as well as the cell surface. To isolate the LCCS antibodies from the mixed population, the liver cells were brought into a single cell suspension and incubated with an equal volume of glutaraldehyde (6.25\%) to form a stroma, following a previously published procedure standardized in our laboratory. ${ }^{30}$ The stroma was used to remove cytosolic antigen-specific antibodies of cancer cells by negative selection. The stroma-bound LCCS antibodies were eluted using propionic acid (1 M, $\mathrm{pH} 2.4)$. The $\mathrm{pH}$ of the eluent was adjusted with TRIS-NaOH ( $3 \mathrm{M}, \mathrm{pH}$ 8.6) and finally extensively dialyzed against $10 \mathrm{mM}$ phosphate buffer at pH 7.4. 


\section{Western blot assay}

Western blot analysis of the tumor cell lysate was carried out in accordance with a published method. ${ }^{28}$ The protein content of each tissue sample was estimated by a routine method using bovine serum albumin as a standard. ${ }^{29}$ Total cell lysate $(30 \mu \mathrm{g})$ was resolved by $10 \%$ sodium dodecyl sulfate polyacrylamide gel electrophoresis and then electroblotted onto nitrocellulose membranes. The blots were blocked overnight with $3 \%$ nonfat dry milk and probed with a rabbit-generated antibody against liver cancer at dilutions of 1:1000. Immunoblots were detected by horseradish peroxidase-conjugated antirabbit IgG using chromogen 3,3'-diaminobenzidine tetrahydrochloride.

\section{Conjugation of gold nanoparticles with LCCS antibody}

The gold nanoparticles synthesized inhouse were conjugated with LCCS antibody by the reaction of $10 \mathrm{~mL}$ colloidal gold solution ( $\mathrm{pH}$ 9.0) with $500 \mu \mathrm{g}$ of purified antibodies. Antibodies were added drop by drop with slow but constant stirring..$^{28}$ The mixture was incubated overnight at $4{ }^{\circ} \mathrm{C}$ and centrifuged the next morning at 10,000 $\mathrm{g}$ for 20 minutes at the same temperature. The pellet was dissolved in a minimum amount of conjugate storage buffer ( $1 \mathrm{mM}$ phosphate buffer of $\mathrm{pH} 7.4$ with $0.05 \%$ Tween 20 ). The binding of antibodies to the nanoparticles was ascertained by the absorption spectra. ${ }^{31}$

\section{Interaction of tumor cells with LCCS antibody-conjugated gold nanoparticles}

Tumor cells were isolated from mice following a standard protocol. ${ }^{28}$ The cells were washed and gently macerated to get a single cell suspension. The accompanying red blood cells were lysed with ACK lysis buffer. Subsequently, the cells $\left(1 \times 10^{6}\right)$ were incubated with antibody $(1 \mu \mathrm{M})$ conjugated with gold nanoparticles for $2-4$ hours at $37^{\circ} \mathrm{C}$ in a $5 \% \mathrm{CO}_{2}$ incubator. Finally, the cells incubated with the antibody were washed with phosphate-buffered solution and transferred onto a glass slide and analyzed under a fluorescence microscope.

\section{Interaction of tumor cells with gold nanoparticle-conjugated LCCS antibody}

The liver cancer cells $\left(1 \times 10^{6}\right)$ were stained with fluorescent probe gold nanoparticle-conjugated antibodies. The cells were incubated for 30 minutes at $4^{\circ} \mathrm{C}$, washed three times with dilution buffer $(0.01 \mathrm{M}$ phosphate buffer saline, $\mathrm{pH} 7.4$ containing $1 \%$ bovine serum albumin, and
$0.1 \%$ sodium azide), and resuspended in $500 \mu \mathrm{L}$ of $2 \%$ paraformaldehyde. The percentage of positive cells was measured using a fluorescence-activated cell sorter (Easycyte Mini; Guava Technologies, Hayward, CA), and the data were analyzed accordingly.

\section{MTT assay}

The HeLa cell line was maintained in RPMI 1640 culture medium supplemented with $10 \%$ heat-inactivated fetal calf serum. The cells were plated at a density of $5 \times 10^{4}$ cells per well in a 96-well plate, and cultured for 72 hours at $37^{\circ} \mathrm{C}$. The cells were subsequently exposed to anticancer drug and LCCS antibody-conjugated gold nanoparticles using a concentration range of $0.01-1 \mu \mathrm{M}$. The plates were incubated for 48 hours, and cell proliferation was measured by adding $20 \mu \mathrm{L}$ of MTT dye ( $5 \mathrm{mg} / \mathrm{mL}$ in phosphate-buffered saline) per well. The plates were incubated for a further 4 hours at $37^{\circ} \mathrm{C}$ in a humidified chamber containing $5 \% \mathrm{CO}_{2}$. Formazan crystals formed due to reduction of dye by viable cells in each well were dissolved in $150 \mu \mathrm{L}$ dimethyl sulfoxide, and absorbance at $570 \mathrm{~nm}$ was read using a SpectraMax M2 plate reader (Molecular Devices, San Jose, CA). Results were expressed as absorbance relative to the plain gold particles used as the control.

\section{Results}

\section{Biomimetic synthesis of gold nanoparticles from gold ions}

The gold nanoparticles were synthesized by incubating $\mathrm{HAuCl}_{4}$ solution with various proportions of cytosolic extract from C. albicans. Incubation of increasing concentrations of $C$. albicans cytosolic extract with solution led to a change in the plasmon resonance band that eventually resulted in the appearance of different colors, from pale yellow to mauve red, after 24 hours (Figure 1C). In the next stage of the study, we evaluated the ability of two reducing agents, glutathione and dithiothreitol, to reduce $\mathrm{HAuCl}_{4}$, leading to formation of nanosized gold structures (Supplementary figure S1).

\section{Ultraviolet-visible near-infrared spectra}

Taking into account the fact that the optical properties of the aqueous suspension of metal nanoparticles are closely associated with their shape, ${ }^{32}$ we recorded ultraviolet-visible near-infrared absorption spectra for the synthesized gold nanoparticles ${ }^{29}$ in aqueous suspension. ${ }^{29}$ The ultravioletvisible absorption spectra of the gold nanoparticles harvested after 24 hours of reaction (Figure 1A) showed two major 

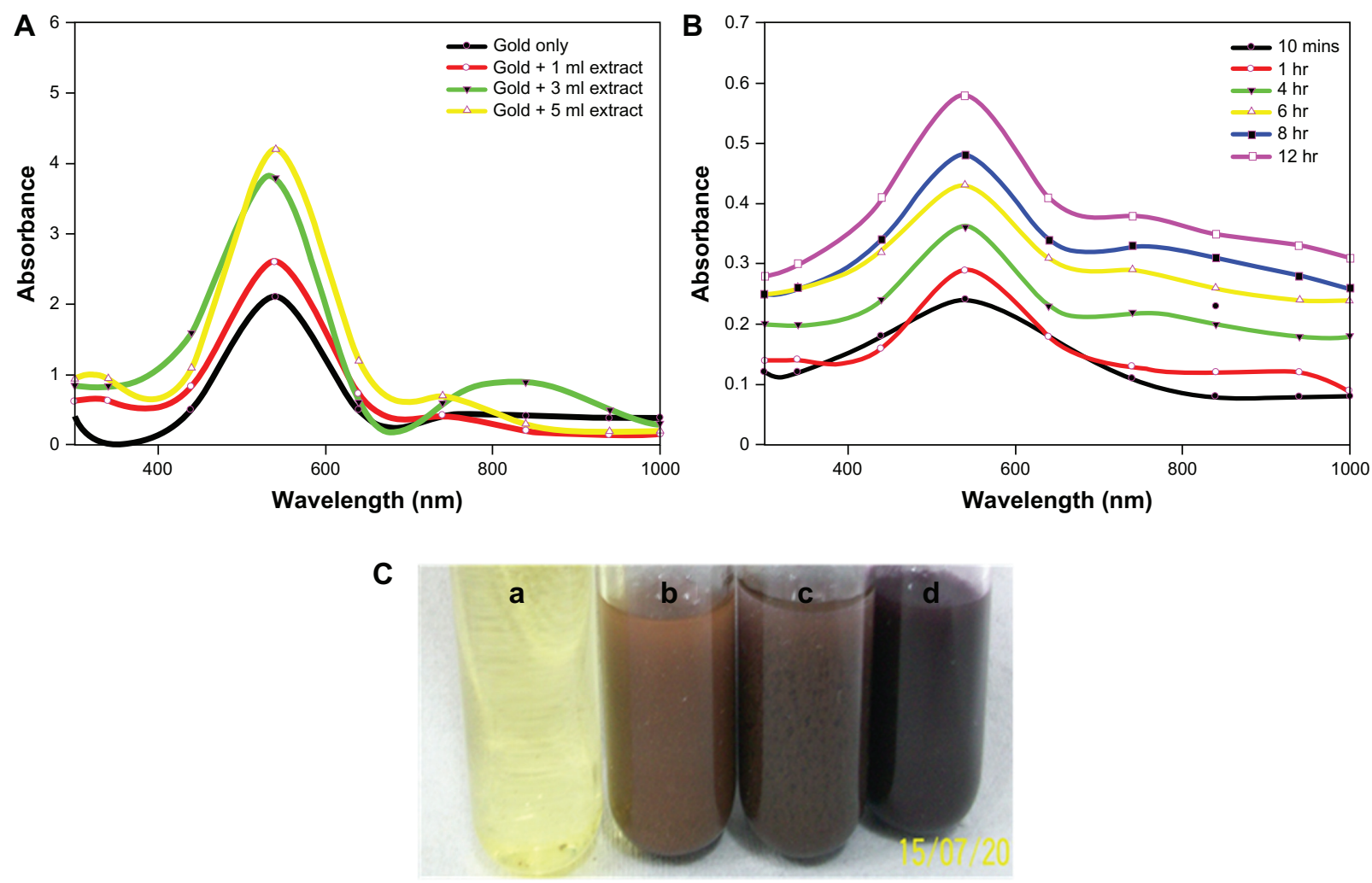

Figure I (A) Ultraviolet-visible-near infrared spectra of gold nanoparticles synthesized by exposing various amounts of Candida albicans cytosolic extract to a fixed volume $(5 \mathrm{~mL})$ of $\mathrm{HAuCl}_{4}$ solution $\left(10^{-3} \mathrm{M}\right)$, keeping the final volume $(10 \mathrm{~mL})$ of reaction mixture for 24 hours. (B) Representative ultraviolet-visible-near infrared spectra depicting kinetics of the reaction of $\mathrm{I} \mathrm{mL}$ of $C$. albicans cytosolic extract with $10 \mathrm{~mL}$ of aqueous $\mathrm{HAuCl}_{4}$ solution for specified time periods. The incubation mixture was scanned in the ultraviolet range to analyze characteristic peaks. (C) Color development as a function of surface plasmon resonance in $C$. albicans cytosolic extract-mediated synthesis of gold nanoparticles. (a) $\mathrm{HAuCl}_{4}$ aqueous solution, (b) Incubation of $5 \mathrm{~mL}$ of $\mathrm{HAuCl}_{4}$ aqueous solution with I mL of $C$. albicans cytosolic extract keeping the final volume of reaction mixture at $10 \mathrm{~mL}$, (c) Incubation of $\mathrm{HAuCl}_{4}$ aqueous solution $(5 \mathrm{~mL})$ with $3 \mathrm{~mL}$ of $C$. albicans cytosolic extract, making the final volume of reaction mixture $10 \mathrm{~mL}$ by adding $2 \mathrm{~mL}$ of deionized water, (d) $5 \mathrm{~mL}$ of $C$. albicans cytosolic extract incubated with $5 \mathrm{~mL}$ of aqueous $\mathrm{HAuCl}_{4}$ solution.

patterns with an increase in the concentration of the extract in the reaction mixture. The first was that the transverse plasmon resonance band that appeared at $540 \mathrm{~nm}$ shifted towards a higher wavelength, confirming a red shift along with amplified absorbance intensity; the second was that the longitudinal plasmon resonance band appearing in the near infrared region of the electromagnetic spectrum at $842 \mathrm{~nm}$ showed a red shift. The ultraviolet-visible spectrum (Figure 1A) also showed a very broad band towards the longer wavelength (infrared) region.

Figure 1B shows the time kinetics of the reaction in terms of ultraviolet-visible near-infrared spectra recorded from the reaction mixture consisting of $1 \mathrm{~mL}$ of $C$. albicans cytosolic extract and aqueous $\mathrm{HAuCl}_{4}\left(10^{-3} \mathrm{M}\right)$, bringing the total volume of reaction mixture to $10 \mathrm{~mL}$. It was observed that, as time progressed, the peak at $540 \mathrm{~nm}$ remained fixed, but the absorbance of the reaction mixture steadily increased to saturation, with no further appearance of any other band at any wavelength. In contrast, the longitudinal plasmon resonance band was seen to change its position with time.

\section{Transmission electron microscopy}

Figure 2 represents a transmission electron micrograph of gold nanoparticles synthesized by the reaction of aqueous chloroaurate ions with different amounts of cytosolic extract of C. albicans after 48 hours of reaction. This is in concordance with the shift in the ultraviolet spectra of the gold nanoparticles. Hexagonal, triangular, and spherical nanoparticles could be seen in the transmission electron micrographs. It was observed that at a lower concentration of cytosolic extract $(1 \mathrm{~mL})$ in the reaction mixture, the average size and number of nonspherical gold particles was larger (Figure 2A and B). At a higher concentration of cytosolic extract $(5 \mathrm{~mL})$, a large number of isomorphic spherical gold nanoparticles of $20-40 \mathrm{~nm}$ in size could be seen in the transmission electron micrographs (Figure 2C and D). The edge length of the nanoparticles was also found to decrease with an increased amount of cytosolic extract.

We also investigated the possibility of controlling particle size by taking a fixed amount of cytosolic extract $(5 \mathrm{~mL})$ for incubation with $10^{-3} \mathrm{M} \mathrm{HAuCl}_{4}$ solution. The size distribution 

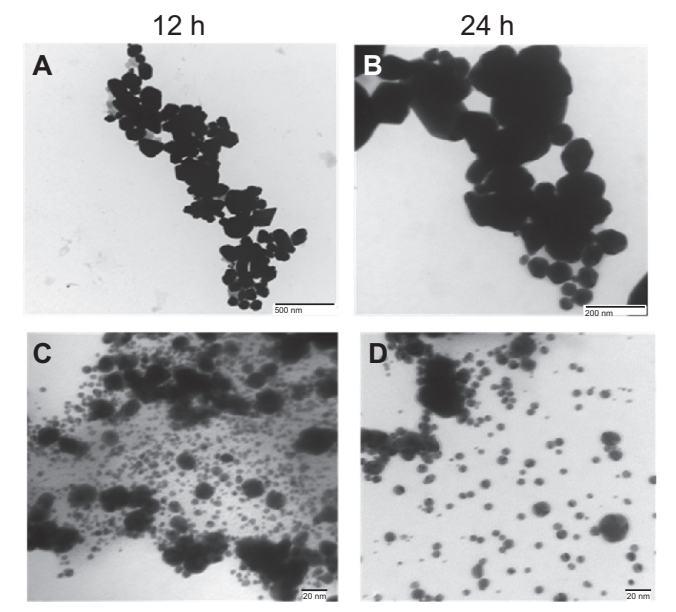

Figure 2 Representative transmission electron micrographs of gold nanoparticles synthesized using various amounts of Candida albicans cytosolic extract. Transmission electron micrographs of gold nanoparticles generated upon incubation of $5 \mathrm{~mL}$ of $\mathrm{HAuCl}_{4}\left(\mathrm{IO}^{-3} \mathrm{M}\right)$ with I $\mathrm{mL}$ of $\mathrm{C}$. albicans cytosolic extract and making up final volume of reaction mixture $(10 \mathrm{~mL})$ using deionized water for $(\mathbf{A}) 12$ hours and (B) 24 hours. (C) and (D) represent transmission electron microscopic images of nanoparticles obtained as a result of reduction of $5 \mathrm{~mL}$ of $\mathrm{HAuCl}_{4}$ solution $\left(10^{-3} \mathrm{M}\right)$ by $5 \mathrm{~mL}$ of cytosolic extract after 12 hours and 24 hours, respectively.

of the gold nanoparticles was observed by digital analysis of image counting of particles, as depicted by the bar diagram in Figure 3A and B. Particles formed at a lower concentration of cytosolic extract were found to be in the size range of 60-80 nm (Figure 3A), while those fabricated with a higher concentration were 20-40 nm (Figure 3B), and this finding is in exact accordance with our transmission electron microscopy data.

\section{Nanophox particle analysis}

Figure 3 shows representative graphs of gold nanoparticles obtained using a nanophox particle analyzer. The size of the gold nanoparticles synthesized using $1 \mathrm{~mL}$ and $5 \mathrm{~mL}$ of cytosolic extract was found to be $61 \pm 5 \mathrm{~nm}$ (Figure 3C) and $23 \pm 5 \mathrm{~nm}$ (Figure 3D), respectively. The observed size patterns are in good agreement with the data provided by ultraviolet spectroscopy and transmission electron microscopy, revealing that the larger-sized nanoparticles were hexagonal and triangular whereas the smaller-sized nanoparticles were spherical.

\section{Atomic force microscopy}

An atomic force microscopic image of the gold nanoparticles synthesized using cytosolic extract $(5 \mathrm{~mL})$ is shown in Figure 4. A number of nanospheres overlapping upon each other are observed in these images. The images in Figures 2D and 3D were both run on the same area of the sample. Uniform surface thickness was observed for the particles. The plane surface plasmon band also confirmed that the thickness was smaller than the triangular edge length. The size of the nanoparticles was found to be $40 \mathrm{~nm}$ when tracked
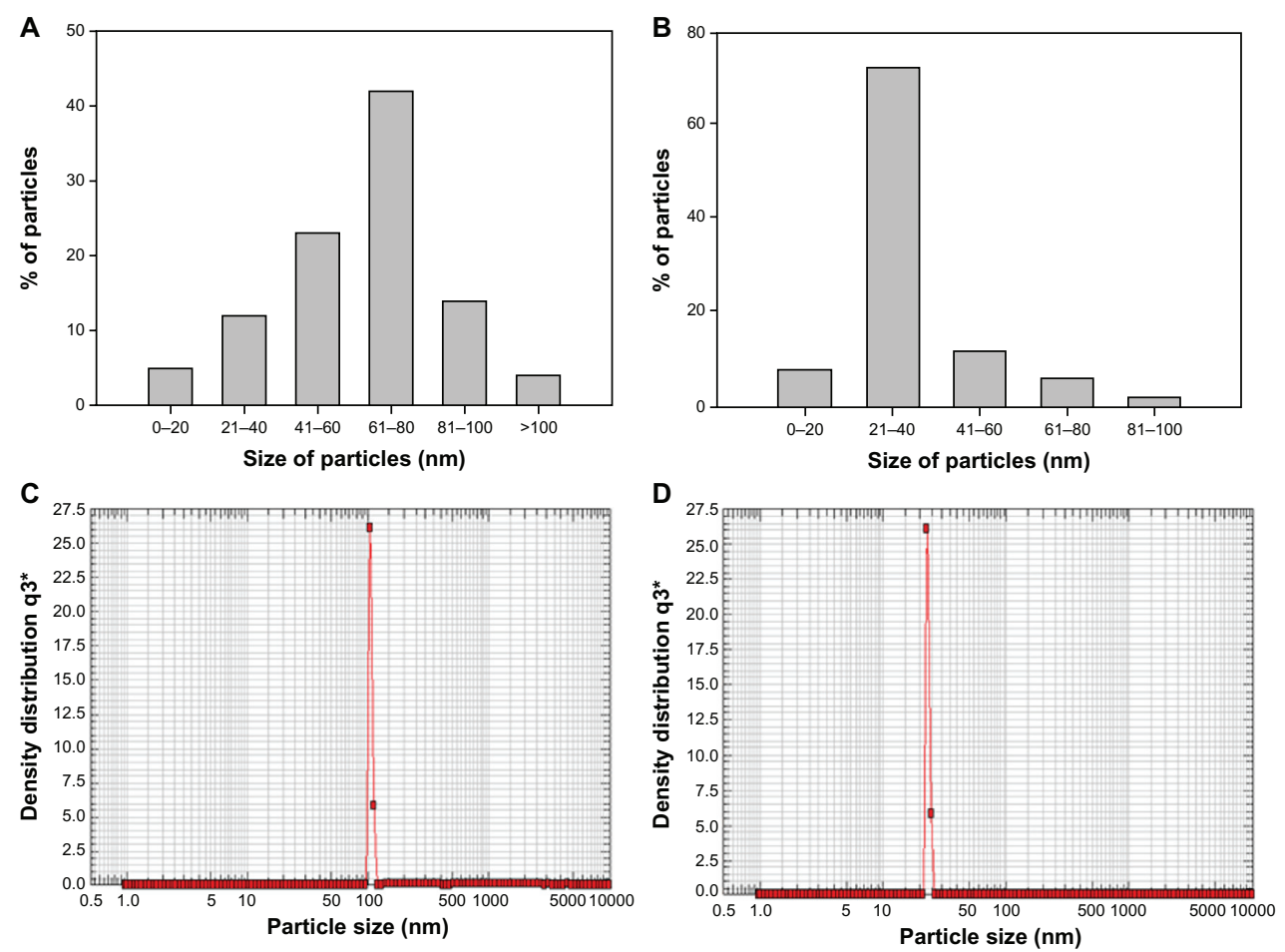

Figure 3 Representative graphs showing variation in particle size distribution upon $24 \mathrm{hrs}$ incubation of $5 \mathrm{ml}$ of $\mathrm{HAuCl}_{4}$ solution $\left(\mathrm{I} 0^{-3} \mathrm{M}\right)$ with $(\mathbf{A}) \mathrm{I} \mathrm{mL}$ and $(\mathbf{B}) 5 \mathrm{~mL}$ of Candida albicans cytosolic extract and keeping final volume of reaction mixture $10 \mathrm{~mL}$. (C) and (D) are representative of particle size analyses of gold nanoparticles synthesized after incubation of $10 \mathrm{~mL}$ of $\mathrm{HAuCl}_{4}\left(10^{-3} \mathrm{M}\right)$ with $\mathrm{I} \mathrm{mL}$ and $5 \mathrm{~mL}$ of cytosolic extract, respectively. 

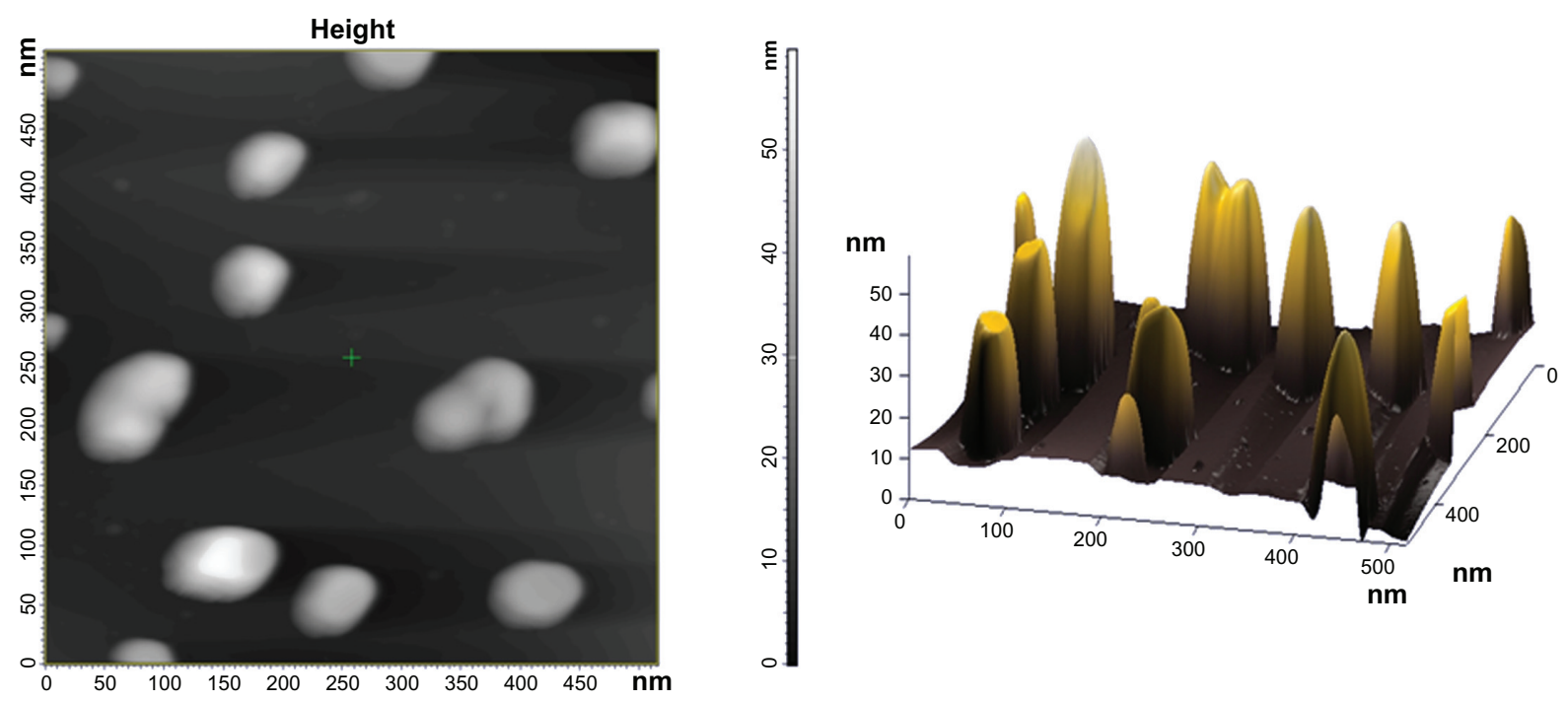

Figure 4 Atomic force microscopy images of gold nanoparticles formed as a result of reduction of $10 \mathrm{~mL} \mathrm{HAuCl}{ }_{4}$ solution (I0-3 $\left.\mathrm{M}\right)$ by $5 \mathrm{~mL}$ of cytosolic extract. The image has been captured after completion of 24 hours of reaction between $\mathrm{HAuCl}_{4}$ and Candida albicans extract. $(\mathbf{A})$ and $(\mathbf{B})$ are representative two-dimensional and threedimensional image, respectively, of gold nanoparticles.

as a two-dimensional image. We also generated height data visualized with single surface three-dimensional atomic force microscopy. For better perception of minute structures, the height of the gold nanoparticles is more noticeable using this technique. The atomic force microscopic image, in concordance with the transmission electron microscopy analysis, showed the presence of a large number of spherical particles at higher concentrations of $C$. albicans cytosolic extract.

\section{Fourier transform infrared spectroscopy}

Fourier transform infrared spectroscopy measurements were carried out to identify the biomolecules and capping reagents in the cytosolic extract that were potentially responsible for the reduction of chloroaurate ions and the stability of the bioreduced nanoparticles, respectively. Figure 5 shows the Fourier transform infrared spectrum of gold nanoparticles reduced by the cytosolic extract. Curve A displays the Fourier transform infrared spectrum of the cytosolic extract, and shows bands in the regions of 3500-3000 $\mathrm{cm}^{-1}$, and $1680-1500 \mathrm{~cm}^{-1}$. It illustrates more peaks at 3087, 3015.04, $3187.91,3211.90,3416.39$, and $3479.95 \mathrm{~cm}^{-1}$. Curve B represents the Fourier transform infrared spectrum of the reduced gold nanoparticles, and shows peaks at 1219, 1623, 1633,1643 , and $1656 \mathrm{~cm}^{-1}$.

\section{Detection of LCCS antibodies by Western blot}

The whole cell lysate used for development of the LCCS antibodies also induced indiscriminate production of antibodies specific for the cytosol as well as the cell surface. To isolate LCCS antibodies specifically from the mixed population, the liver cells were brought to a single cell suspension following a published procedure ${ }^{30}$ exploiting glutaraldehyde cross-linked stroma. This strategy led to the removal of cytosol-specific antibodies by negative selection. The stroma-bound LCCS antibodies were eluted by propionic acid (1 M, pH 2.4). The $\mathrm{pH}$ of the eluent was adjusted with Tris- $\mathrm{NaOH}(1 \mathrm{M}, \mathrm{pH}$ 8.6). Production of antibodies against the cell lysate of liver cancer was first confirmed by Western blot analysis. Crossreactivity of the LCCS antibody against a sample protein obtained from a cell lysate of liver cancer was observed on the blot, which indicated production of the desired antibody. The antibody generated against the liver cancer cell was found to recognize more than one band (protein) of the cell lysate (Figure 6B).

\section{Conjugation of LCCS antibody with gold nanoparticles}

The negative charge imparted to the biogenic gold nanoparticles as a consequence of their capping with a protein layer revealed by Fourier transform infrared spectroscopy data could be targeted for charge-based bioconjugation. Bioconjugation of antibodies to the nanoparticles was demonstrated by ultraviolet spectroscopic analysis of the gold nanoparticles. A shift in peak towards a longer wavelength (from $540 \mathrm{~nm}$ to $552 \mathrm{~nm}$ ) following conjugation of the LCCS antibodies to the nanoparticles was observed, as shown in Figure 6A. 


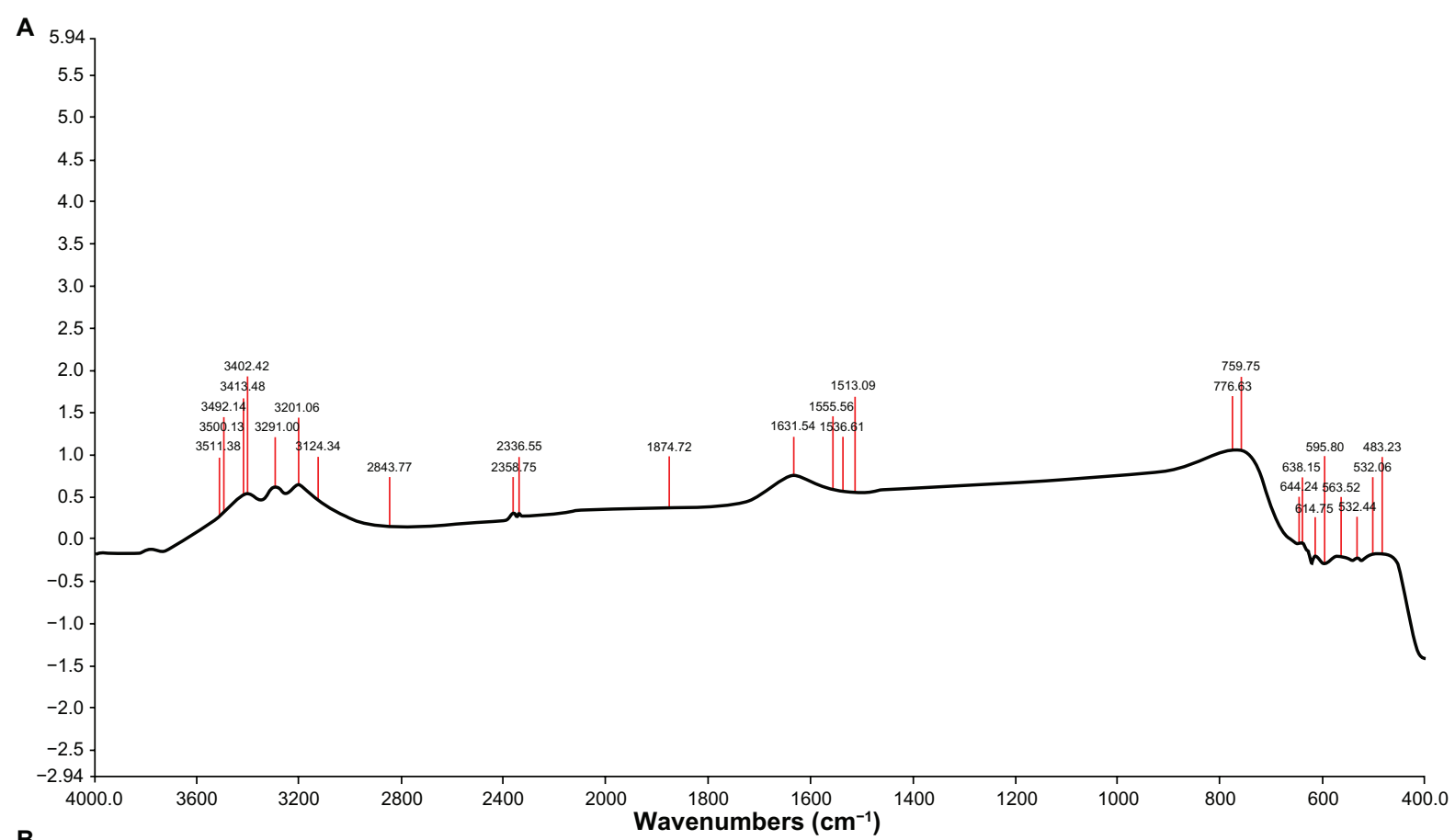

B

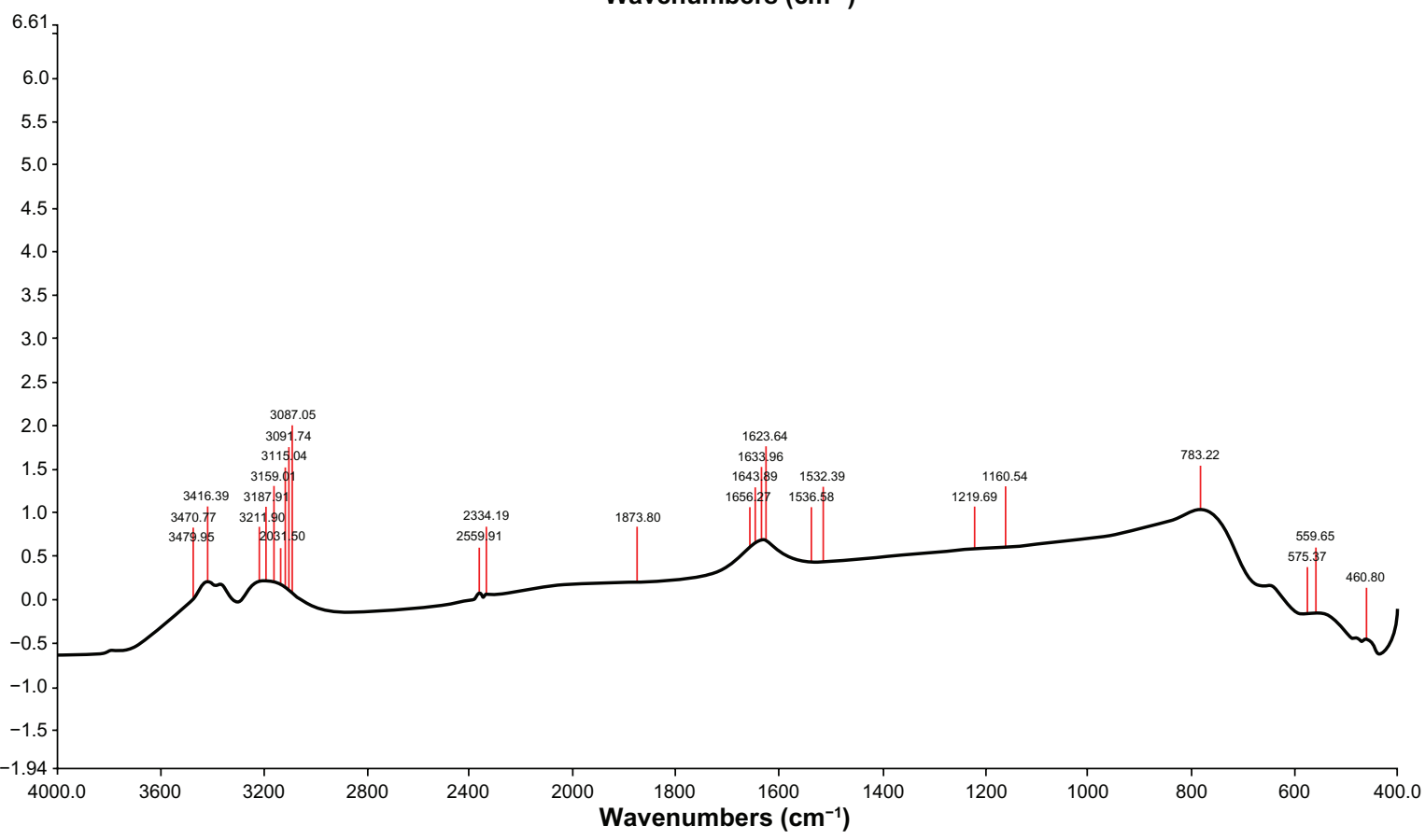

Figure 5 Typical Fourier transform infrared spectra of gold nanoparticles synthesized using Candida albicans cytosolic extract. Curve (A) represents Fourier transform infrared spectra of cytosolic extract of C. albicans and curve (B) represents Fourier transform infrared spectra of gold nanoparticles obtained by the reduction of $5 \mathrm{~mL} \mathrm{HAuCl}{ }_{4}$ $\left(10^{-3} \mathrm{M}\right)$ by $I \mathrm{~mL}$ of $C$. albicans cytosolic extract. Spectra were obtained after a 24-hour incubation period.

\section{Interaction of tumor cells with LCCS} antibody-conjugated gold nanoparticles

LCCS antibody-conjugated gold nanoparticles were used to probe the liver cancer cells. Figure 7 shows fluorescent microscopic images of the LCCS antibody-conjugated gold nanoparticles adhering to liver tumor cells. Fluorescence restricted to the cell surface is observed. Tumor cells incubated with the nonspecific antibody did not show any fluorescence (panel B in Figure 7). Fluorescent-activated cell sorting analysis further ascertained the ability of LCCS antibody-conjugated gold nanoparticles to recognize liver cancer cells specifically. The dot plot analysis (Figure 9) gives an estimate of the liver cancer cell population in the liver homogenate. 

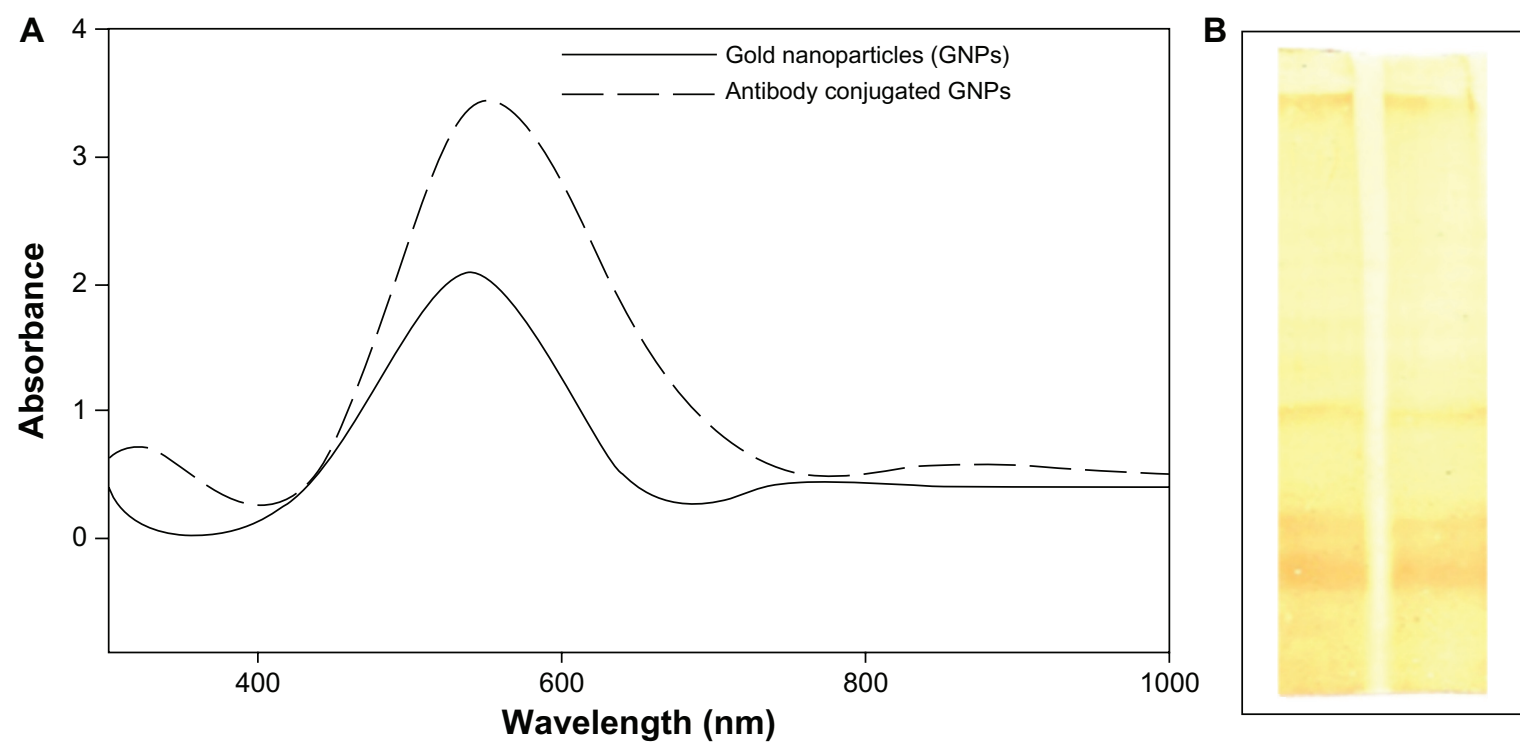

Figure 6 (A) Ultraviolet spectroscopic analysis $(500-580 \mathrm{~nm})$ for pure gold nanoparticles and nanoparticles conjugated to antibody. (B) Western blot analysis of specific antibody raised against surface markers of a liver cancer cell.

\section{Cellular uptake of nanoparticles by antigen-presenting cells}

Macrophages isolated from the peritoneal cavity of thioglycolate-primed BALB/c mice were used to assess the uptake of gold nanoparticles. Interaction of the LCCS antibodyconjugated gold nanoparticles with macrophages resulted in uptake of the nanoparticles by endocytosis, which mainly appeared in the form of punctate fluorescence (Figure 8).
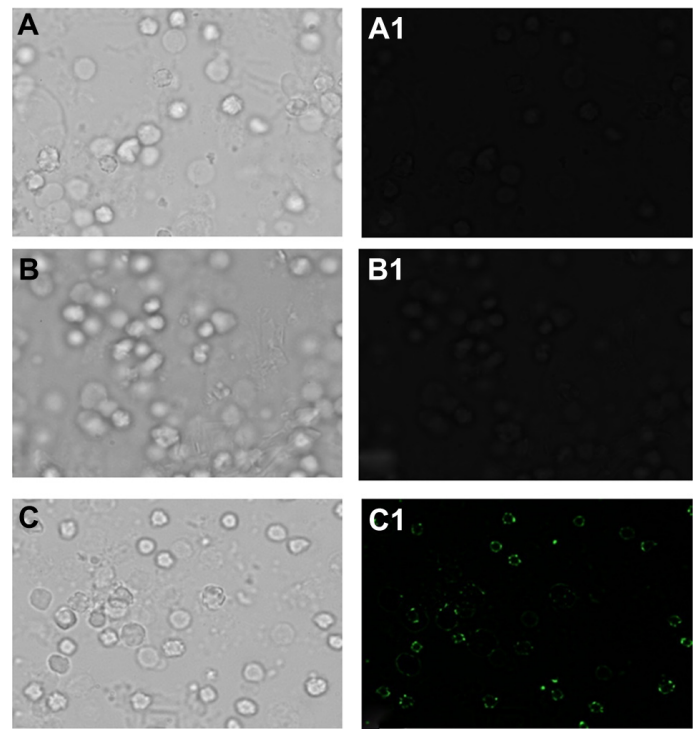

Figure 7 Fluorescence microscopy of tumor cells employing gold nanoparticle conjugated with antibody-generated against liver tumor cell surface proteins. ( $\mathbf{A}$ and $\mathbf{A} \mathbf{I}$ ) liver tumor cells only (B and B I) Nonspecific antibody incubated with liver cancer cell captured by using phase contrast and fluorescein isothiocyanate filter, $(\mathbf{C}$ and $\mathbf{C I})$ gold nanoparticles conjugated with liver cancer cell surface-specific antibodies upon their incubation with gold particles, phase contrast and fluorescein isothiocyanate filter images.

\section{Cytotoxic potential of gold nanoparticles}

The cytotoxic potential of the gold nanoparticles formed against the cancer cell line was assessed by determining the number of viable cells surviving after incubation with the gold nanoparticles for the stipulated time period using the MTT method..$^{33}$ The cytotoxicity assay suggests that the cytotoxicity of the gold nanoparticles was variable when they were conjugated with antibodies and anticancer drugs. Anticancer drug-conjugated gold nanoparticles exhibited the highest cytotoxicity, followed by the antibody-conjugated gold nanoparticles. A $1 \mu \mathrm{M}$ sample of anticancer drug-conjugated and antibody-conjugated gold nanoparticles were found to be highly toxic to the cells (Supplementary figure S2).

\section{Fluorescence spectroscopy}

Fluorescence spectra of the LCCS antibody-conjugated gold nanoparticle solution at different time points (10 minutes to 24 hours) were collected and are shown in Figure 10A. It can be seen that the fluorescence intensity amplifies with increasing time, but that the increase is more pronounced at the 24-hour time point when compared with 12 hours. The fluorescence of the LCCS antibody-conjugated gold nanoparticles relative to that of naïve gold particles was also evaluated, and was found to increase steadily with an increasing concentration of conjugated antibody (Figure 10B).

\section{Discussion}

Advancement in the field of nanotechnology is expected to have a large socioeconomic impact in practically all industrial 


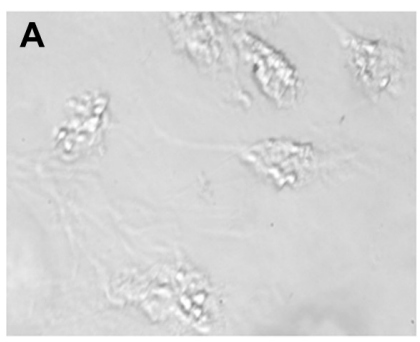

B

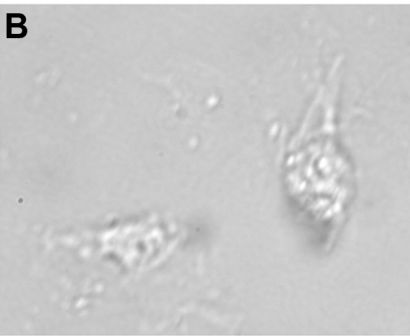

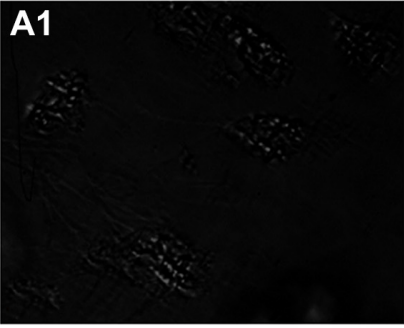

B1

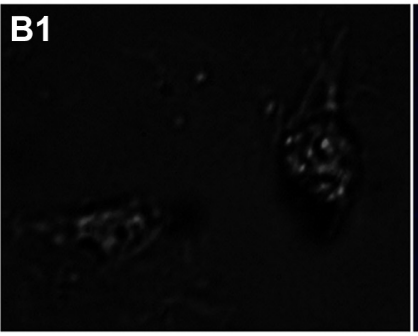

A2

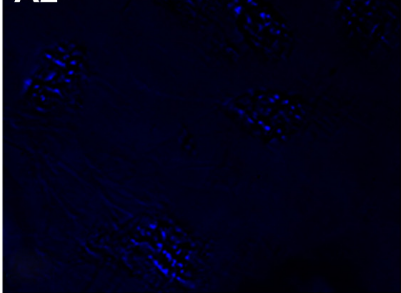

B2

Figure 8 Fluorescence micrographs showing interaction of macrophages incubated with gold nanoparticles conjugated with liver cell surface-specific antibodies. Upper and lower panels show the micrographs captured after 2 and 4 hours of incubation, respectively, in bright field, phase contrast and DAPI filter. Punctate fluorescence is observed due to endocytosis mediated-uptake of gold nanoparticles by macrophages.

sectors, particularly in biomedicine, with specific application in diagnostics and therapeutics. Currently, there is an urgent need to develop biosynthetic procedures for nanoparticle synthesis as an alternative to toxic, eco-hazardous, and highcost synthetic procedures. The present study focuses on the biogenic synthesis of gold nanoparticles using a cytosolic extract of $C$. albicans and evaluates their potential to differentiate cancer cell populations from normal cells when conjugated with a liver cancer cell antibody.

The data from the present study demonstrate that gold particles are formed as a result of reduction of chloroaurate ions to gold particles of nanodimensions by a cytosolic extract of $C$. albicans. Bioreduction is the foremost mechanism in metal nanoparticle synthesis. ${ }^{22}$ Many proteins, carbohydrates, and biomembranes are involved in microbial bioreduction processes. ${ }^{34}$ In intact cells, nanoparticles are formed on cell wall surfaces, and the first step in bioreduction is the trapping of metal ions on this surface. This may be followed by enzymatic reduction of the metal ions, leading to their aggregation and formation of nanoparticles. ${ }^{35}$ It has been reported that a microbial cell reduces metal ions via specific reducing enzymes, such as NADH-dependent reductase or nitrate-dependent reductase. ${ }^{36}$ However, when present in cytosolic extracts of cells, these enzymes might come into contact with various cell components, leading directly to their rapid reduction to nanodimension particles. Oxidoreductases in yeast, NADH-dependent reductase in Fusarium oxysporum and Aspergillus flavus, nitrate-dependent reductase in
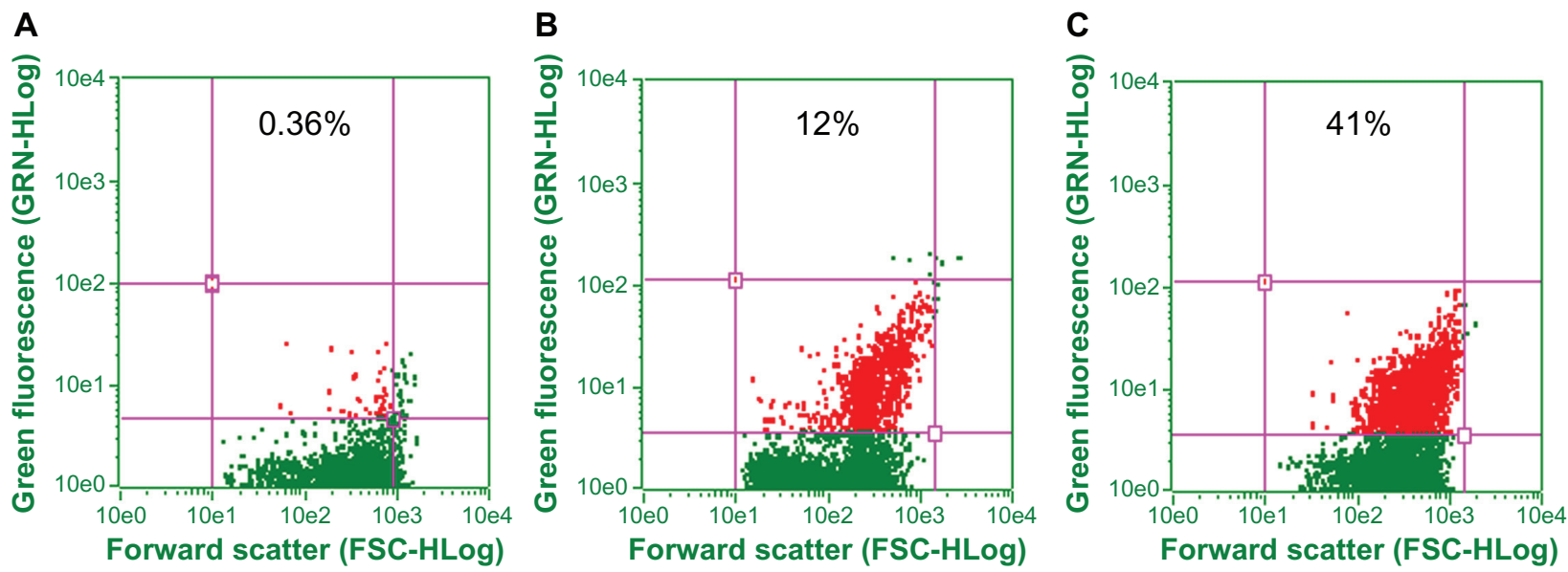

Figure 9 Interaction of liver cancer cells with gold nanoparticle conjugated anti-lccsAb employing fluorescence-activated cell sorting analysis. The cells with log fluorescence intensities $>10^{\prime}$ were gated as gold nanoparticle-conjugated antibody and liver tumor. (A) Liver tumor cells only, (B) nonspecific antibody incubated with liver cancer cell, and (C) gold nanoparticle-conjugated cell surface-specific antibody incubated with liver cancer cells. 

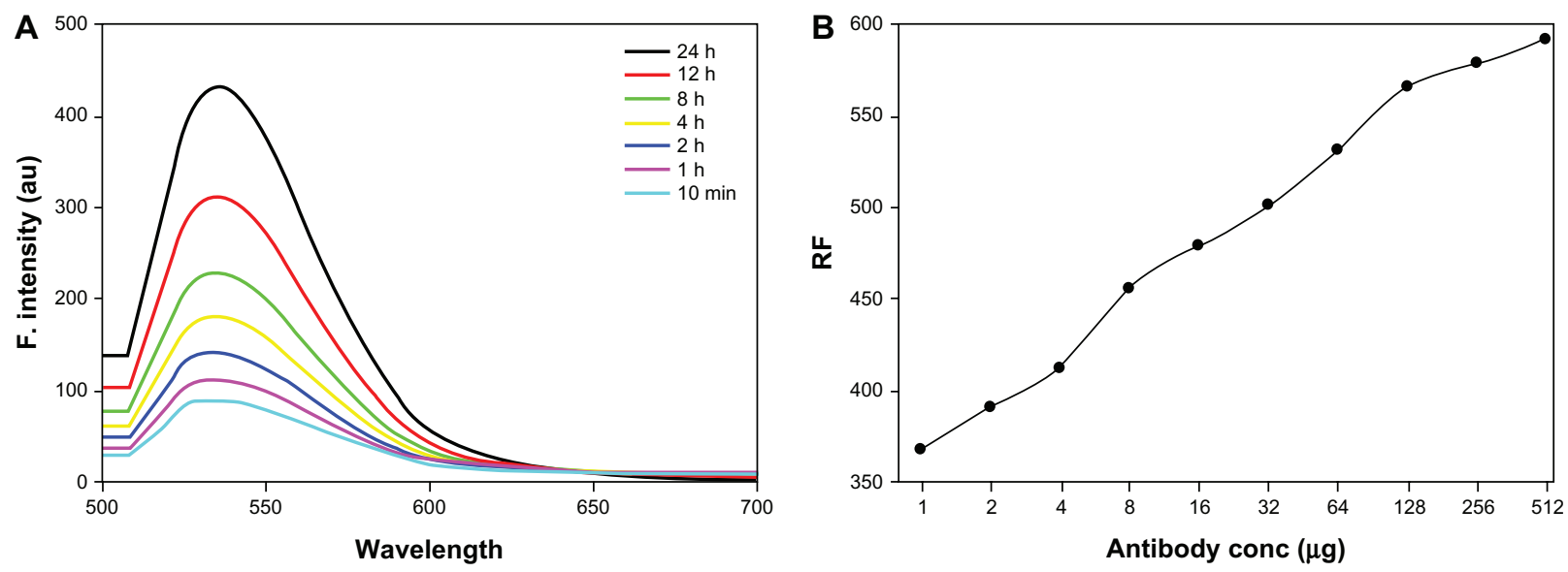

Figure 10 (A) Fluorescence spectra of antibody-conjugated gold nanoparticles at various specified time points. (B) Relative fluorescence of antibody-conjugated gold particles to that of plain gold particles as a function of relative increase in amount of conjugated antibody concentration.

Fusarium oxysporum, cationic proteins of around $55 \mathrm{kDa}$ in Verticillium sp, and glutathione, as well as glutathionelike compounds, phytochelatins and metallothioneins in Saccharomyces cerevisiae, Schizosaccharomyces pombe, and Candida glabrata, have been found to be elegantly involved in the reduction of metal ions to nanoparticles. ${ }^{37}$ Along with these, a number of simple hydroxyl/methoxy derivatives of benzoquinones and toluquinones are elaborated for lower fungi, especially Penicillium and Aspergillus. ${ }^{37}$ It is anticipated that $C$. albicans, being a fungus, might also be amongst such compounds, facilitating reduction of metal ions.

In view of the present data enumerating the role of glutathione in reduction of gold ions to gold particles (Supplementary figure S1), it is speculated that glutathione and the glutathione-like compound, phytochelatin (metal binding ligand) mainly cause the formation of gold nanoparticles. Glutathione is a structural unit in phytochelatin molecules. Phytochelatins have the general structure (c-Glu-Cys) n-Gly, and are formed by a transpeptidation reaction of $c$-Glu-Cys dipeptide from a glutathione molecule to a second molecule of glutathione, resulting in a phytochelatin molecule. It has been reported that phytochelatin synthesis begins within minutes of exposure of living cells to metal ions, and is regulated by enzymatic activation in the presence of metal ions. ${ }^{38}$ We speculate from this observation that as soon as gold ions are exposed to the cytosolic pool of glutathione, phytochelatin synthesis is initiated, and that both these molecules subsequently result in formation of metal thiolate complexes, reducing the gold ions and thus forming nanocrystals. Studies have also illustrated the use of glutathiones as capping agents for gold quantum clusters (AU-n-SG-m), ie, glutathione thiolate, for the stability of
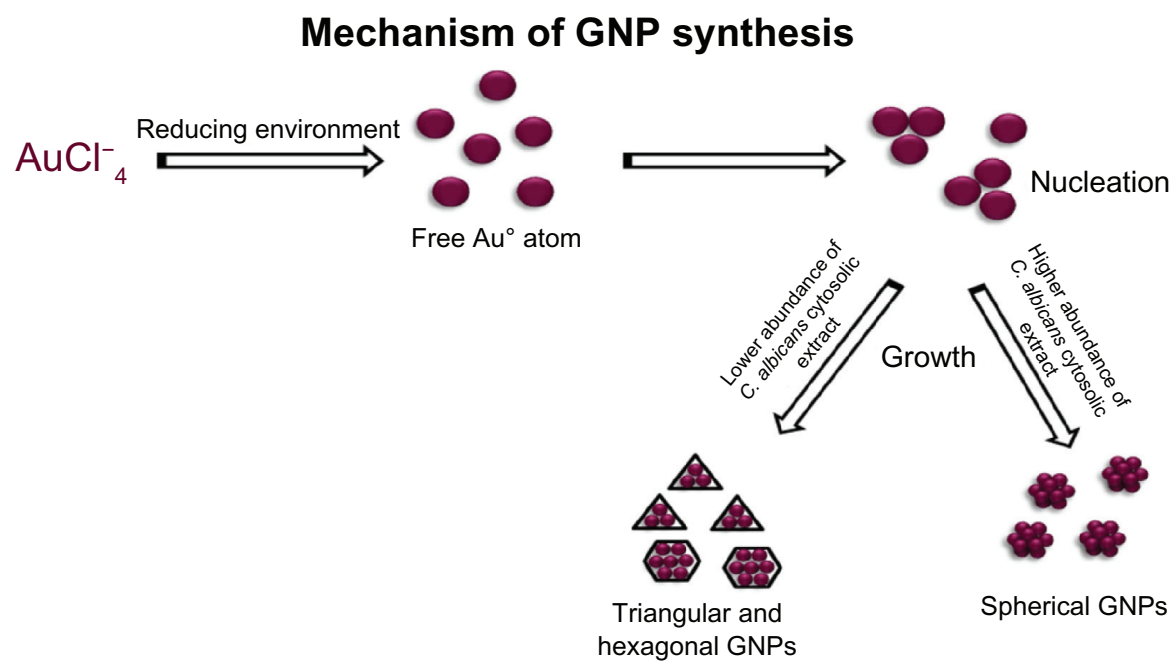

Figure I I Mechanism of $C$. albicans cytosol mediated gold nanoparticles. Abbreviation: GNPs, Gold Nanoparticles. 
gold nanoparticles synthesized chemically. ${ }^{39}$ In addition, the electrons present in the conduction band of nanoparticulate gold make them potent binders of thiols and amines. ${ }^{39}$

The formation of nanostructures was confirmed by the development of a pale yellow to wine red color when an increased amount of cytosolic extract of C. albicans was added (Figure 1C). The observed pink to red color is a characteristic of the surface plasmon resonance associated with gold nanoparticles ${ }^{40}$ of different sizes in solution. To characterize the synthesized gold nanoparticles further, various spectroscopic analyses along with transmission electron and atomic force microscopy studies were carried out. The data obtained confirmed the fabrication of nonspherical nanoparticles at a lower concentration and spherical particles at a higher concentration of cytosolic extract.

A red shift and amplified absorption intensity in the transverse plasmon resonance band with an increase in the amount of cytosolic extract (Figure 1A) is indicative of an increase in the number of spherical gold nanoparticles in the reaction mixture. ${ }^{41}$ This was confirmed by the transmission electron microscopy images discussed subsequently, wherein a large number of spherical nanoparticles are seen to be present, along with a few triangular and hexagonal nanoparticles at a higher concentration of cytosolic extract of $C$. albicans. The presence of a longer wavelength longitudinal plasmon band at $840 \mathrm{~nm}$ in the ultraviolet-visible near infrared spectra can be attributed to anisotropy in the nanoparticles, ${ }^{41}$ which coincides well with the hexagonal and triangular shape of nanoparticles shown in the transmission electron microscopy images. In fact, ultraviolet-visible absorption of uniquely shaped nanoparticles usually shows a red shift and a wider peak when compared with spherical gold nanoparticles. The broad band (Figure 1A) towards a longer wavelength region might be because of the rapid reduction of gold ions at a higher concentration of cytosolic extract leading to the formation of rod-shaped nanoparticles.

The nonshifting of the peak wavelength during the time-kinetics study of the reaction is indicative of a need to monitor concentrations of gold nanoparticles and consequent conversion by measuring the absorbance at $540 \mathrm{~nm}$. The time-dependent characteristics of the ultraviolet spectra reveal either aggregation of spherical gold nanoparticles ${ }^{42}$ or formation of anisotropic nanoparticles. ${ }^{43}$ The time-dependent saturation of increased absorption at $540 \mathrm{~nm}$ suggests complete reduction of the gold ions. The altered position of the longitudinal plasmon band with time indicates a change in the composition of the sample and suggests the possibility of formation of triangular nanoparticles (Figure 1B).
Transmission electron micrographs obtained using different amounts of cytosolic extract to reduce the gold ions show the appearance of hexagonal, triangular, and spherical nanoparticles. This is in concordance with the shift in the ultraviolet spectra of the gold nanoparticles. The transmission electron microscopy images suggest that the ratio of cytosolic extract (reducing agent) and the $\mathrm{HAuCl}_{4}$ solution might be playing a crucial role in regulating the shape of the generated nanoparticles. An inverse dependence of concentration of cytosolic extract on the appearance of nonspherical nanoparticles is seen. The ratio of the number of spherical nanoparticles to triangular and hexagonal particles was found to increase with an increasing amount of cytosolic extract. A lower concentration of cytosolic extract favored the formation of larger nonspherical nanoparticles (Figure 2A and B) while at a higher concentration a number of isomorphic spherical nanoparticles of size 20-40 nm were formed, as seen in the transmission electron microscopy images (Figure 2C and D). A decrease in particle size with an increase in the amount of cytosolic extract was also identified by digital analysis of image counting of particles, as depicted by the bar diagrams in Figure 3A and B. Most of the particles were found to be in the size range of $20-40 \mathrm{~nm}$ at a higher concentration of cytosolic extract, which further supports our transmission electron microscopy data. Nanophox particle analysis (Figure 3C and D) and atomic force microscopy data (Figure 4) also show concomitant results, with a higher content of cytosolic extract favoring the formation of smaller spherical nanoparticles while a lower amount leads to generation of larger triangular and hexagonal particles.

Fourier transform infrared measurements confirm the role of phenolic and alcoholic compounds in the reduction of gold ions and protein as the stabilizing material for the generated nanoparticles, as revealed by shoulders in the region of $3500-3000 \mathrm{~cm}^{-1}$, which are characteristic of hydroxyl stretch vibrations in phenolic and alcoholic compounds. The peak in the region of $1680-1500 \mathrm{~cm}^{-1}$ is attributed in combination to the amide band of proteins and to stretching vibrations in the secondary structure of proteins, establishing the role of proteins as a capping material (Figure 5).

Electrostatic interaction between the antibodies and gold nanoparticles was feasible. ${ }^{44}$ Hence, in the next phase of the study, antibodies generated against liver cancer cell surface antigens were targeted for conjugation with nanoparticles and were subsequently used to probe liver cancer cells. The observed $12 \mathrm{~nm}$ shift towards a longer wavelength is in agreement with the well known fact that nanoparticles show a shift in their absorption wavelength 
when conjugated with a chemical or biological molecule ${ }^{45}$ (Figure 6A).

Surface plasmon resonance is responsible for the intense colors exhibited by a colloidal solution of noble metals and can be attributed to the collective oscillations of surface electrons induced by visible light ${ }^{46}$ Molecular binding of an antibody to the surface of a gold nanoparticle is transduced to a colorimetric signal due to the changes in surface plasmon absorbance of the parent gold particle. Eventually, binding at the surface of functionalized gold particles results in a shift in peak wavelength as well as an increase in intensity (Figure 10A). The observed effect was found to be regulated by the amount of antibody used. Thus, with an increase in the amount of conjugated antibody, there was an increase in the intensity of the peak (Figure 10B). The gold nanoparticle-conjugated antibodies were used as a probe to detect liver cancer cells. Cell surface-restricted fluorescence is observed in the image (Figure 7). Panel B of the micrograph for the tumor cells incubated with the nonspecific antibody does not show any fluorescence. The potential of antibodyconjugated gold nanoparticles to recognize liver cancer cells specifically was further confirmed by fluorescence-activated cell sorting analysis. The interaction of the antibody-conjugated gold nanoparticles with the surface molecules of cancer cells assists them to acquire fluorescence that can be exploited for specific detection of liver cancer cells (Figure 9).

Interaction of antibody-conjugated gold nanoparticles with macrophages was also monitored in order to rule out the possibility of antibody-conjugated gold nanoparticles being recognized by surface molecules of cells other than liver cancer cells. The interaction studies show uptake of antibodyconjugated gold nanoparticles by endocytosis, appearing mainly in the form of punctuate fluorescence (Figure 8). This clearly suggests that the antibody-conjugated gold nanoparticles are not recognized by cell surface molecules or macrophages and serve as proof of the concept that this gold nanoparticle-based probe can serve as a simple diagnostic tool to differentiate between normal cells and cancer cells. Cytotoxicity of gold nanoparticles (both plain as well as conjugated to antibody and anticancer drug) was assessed against cancer cells using the MTT cytotoxicity assay (Supplementary figure S2). Concentration-dependent cytotoxicity was measured by determining the number of viable cells surviving after their incubation with the gold particles. Antibody-conjugated gold particles showed negligible cytotoxicity, with percentage cell viability being approximately $90 \%$ at $0.01 \mu \mathrm{M}$. However, they were found to be highly cytotoxic at a concentration of $1 \mu \mathrm{M}$. This reveals that $10-100 \mathrm{nM}$ gold nanoparticles conjugated with an anticancer antibody can successfully probe cancer cells with minimal cytotoxicity, and can be employed for in vivo imaging of liver cancer after appropriate advancement of the strategy.

\section{Conclusion}

Particles of nanosize dimensions are desirable owing to their medical and biotechnological applications, but the major concern with them is the health hazards that their synthesis might pose. This has driven the development of biologically inspired synthesis of nanoparticles. We report here the biogenic synthesis of gold nanoparticles employing a novel source, ie, a cytosolic extract of C. albicans, which was found to be simple, economically viable, and environment friendly. We also infer from our study that the shape and size of the nanoparticles formed govern the characteristic features of their spectra. The size and number of nonspherical nanoparticles were found to be inversely proportional to the amount of cytosolic extract, and it was also deduced that a higher concentration of cytosolic extract favored the formation of spherical nanoparticles. These were confirmed by the concordant results of ultraviolet spectroscopy, transmission electron microscopy, atomic force microscopy, and Nanophox analysis. Fourier transform infrared spectroscopy data suggest the role of proteins in capping the gold nanoparticles for the purpose of stabilization.

Cancer cell surface-specific antibodies generated in mice against induced liver cancer were conjugated with the synthesized gold nanoparticles and exploited to distinguish between normal and cancerous cells. Antibody-conjugated gold nanoparticles were found to bind unambiguously to LCCS surface markers and, hence, were able to probe liver cancer cells successfully. Indeed, tagging of antibody conjugated with gold nanoparticles onto the tumor cell surface is a significant result, because gold nanoparticles are novel nanocarriers able to carry antibodies. The technique can be extended for rapid, specific, and cost-effective detection of various cancers, hormones, pathogenic microbes, and their toxins if a specific antibody is available.

\section{Acknowledgments}

The authors thank Professor M Saleemuddin of the Interdisciplinary Biotechnology Unit for providing us with research facilities. We acknowledge the Department of Biotechnology, Government of India, for financial support to conduct this study. We are thankful to Professor Akhtar Mahmood, Central Instrumentation Facilities, Punjab University, Chandigarh, for helping us with our electron microscopy studies. We are also thankful to JN Agrewala, Institute of Microbial Technology, Chandigarh. 


\section{Disclosure}

The authors report no conflicts of interest in this work.

\section{References}

1. Krolikowska A, Kudelski A, Michota A, Bukowska J. SERS studies on the structure of thioglycolic acid monolayers on silver and gold. Surf Sci. 2003;532:227-232.

2. Kumar A, Mandal S, Selvakannan PR, Parischa R, Mandale AB, Sastry M. Investigation into the interaction between surface-bound alkylamines and gold nanoparticles. Langmuir. 2003;19:6277-6282.

3. Chandrasekharan N, Kamat PV. Improving the photoelectrochemical performance of nanostructured $\mathrm{TiO}_{2}$ films by adsorption of gold nanoparticles. J Phys Chem B. 2000;104:10851-10857.

4. Peto G, Molnar GL, Paszti Z, Geszti O, Beck A, Guczi L. Electronic structure of gold nanoparticles deposited on $\mathrm{SiOx} / \mathrm{Si}(100)$. Mater Sci Eng C. 2002;19:95-99.

5. Sastry M, Ahmad A, Khan MI, Kumar R. Biosynthesis of metal nanoparticles using fungi and actinomycete. Curr Sci. 2003;85:162-170.

6. Ankamwar B, Chaudhary M, Sastry M. Gold nanoparticles biologically synthesized using tamarind leaf extract and potential application in vapor sensing. Synth React Inorg M. 2005;35:19-26.

7. Ahmad A, Senapati S, Khan MI, et al. Intracellular synthesis of gold nanoparticles by a novel alkalotolerant actinomycete, rhodococcus species. Nanotechnology. 2003;14:824-828.

8. Simkiss K, Wilbur KM. Biomineralization. New York: Academic Press; 1989.

9. Mann S, editor. Biomimetic Materials Chemistry. New York, NY: VCH Publishers; 1996.

10. Lovley DR, Stolz JF, Nord GL, Philips EJP. Anaerobic production of magnetite by a dissimilatory iron-reducing microorganism. Nature. 1987;330:252-254.

11. Spring H, Schleifer KH. Diversity of magnetotactic bacteria. Syst Appl Microbiol. 1995;18:147-153.

12. Dickson DPE. Nanostructured magnetism in living systems. J Magn Magn Mater. 1999;203:46-49.

13. Mann S. Molecular tectonics in biomineralization and biomimetic materials chemistry. Nature. 1993;365:499-505.

14. Oliver S, Kupermann A, Coombs N, Lough A, Ozin GA. Lamellar aluminophosphates with surface patterns that mimic diatom and radiolarian microskeletons. Nature. 1995;378:47-50.

15. Kroger N, Deutzmann R, Sumper M. Polycationic peptides from diatom biosilica that direct silica nanosphere formation. Science. 1999;286: 1129-1132.

16. Stephen JR, MacNaughton SJ. Developments in terrestrial bacterial remediation of metals. Curr Opin Biotechnol. 1999;10:230-233.

17. Mehra RK, Winge DR. Metal ions resistance in fungi: molecular mechanisms and their regulated expression. J Cell Biochem. 1991; 45:30-40.

18. Beveridge TJ, Murray RGE. Site of metal deposition in the cell wall of Bacillus subtilis. J Bacteriol. 1980;141:876-887.

19. Southam G, Beveridge TJ. The occurrence of sulfur and phosphorus within bacterially derived crystalline and pseudocrystalline octahedral gold formed in vitro. Geochim Cosmochim Acta. 1996;60: 4369-4376.

20. Nair B, Pradeep T. Coalescence of nanoclusters and formation of submicron crystallites assisted by Lactobacillus strains. Cryst Growth Des. 2002;2:293-298.

21. Ahmad A, Mukherjee P, Senapati S, et al. Extracellular biosynthesis of silver nanoparticles using the fungus Fusarium oxysporum. Colloids Surf B Biointerfaces. 2003;28:313-318.

22. Moghaddam KM. An introduction to microbial metal nanoparticle preparation method. The Journal of Young Investigators. 2010;19.

23. Campas M, Katakis I. Characterization and determination of stability and functionality of biofunctionalised colloidal gold nanoparticles. Anal Chim Acta. 2006;556:306-312.
24. Yang L, Xing RM, Shen QM, et al. Fabrication of protein-conjugated silver sulfide nanorods in the bovine serum albumin solution. J Phys Chem B. 2006;110:10534-10539.

25. Lisa M, Chouhan RS, Vinayaka AC, Manonmani HK, Thakur MS. Gold nanoparticles based dipstick immunoassay for the rapid detection of dichlorodiphenyltrichloroethane: An organochlorine pesticide. Biosens Bioelectron. 2009;25:224-227.

26. Germain V, Li J, Ingert D, Wang Z, Pileni MP. Stacking faults in formation of silver nanodisks. J Phys Chem B. 2003;107:8717-8720.

27. Pitot HC, Barsness L, Goldsworthy T, Kitagawa T. Biochemical characterisation of stages of hepatocarcinogenesis after a single dose of diethylnitrosamine. Nature. 1978;271:456-458.

28. Towbin H, Staehelin T, Gordon J. Electrophoretic transfer of proteins from polyacrylamide gels to nitrocellulose sheets: procedure and some applications. Proc Natl Acad Sci U S A. 1979;76:4350-4354.

29. Lowry OH, Rosenbrough NK, Farr AL, Randall RJ. Protein measurement with folin phenol reagent. J Biol Chem. 1951;193:265-275.

30. Owais M, Varshney GC, Choudhury A, Chandra S, Gupta CM. Chloroquine encapsulated in malaria-infected erythrocyte specific antibody bearing liposomes effectively controls chloroquine resistant Plasmodium berghei infections in mice. Antimicrob Agents Chemother. 1995;39:180-184.

31. Vinayaka AC, Basheer S, Thakur MS. Bioconjugation of CdTe quantum dot for the detection of 2, 4-dichlorophenoxyacetic acid by competitive fluoroimmunoassay based biosensor. Biosens Bioelectron. 2009;24: $1615-1620$

32. Wiley BJ, Im SH, McLellan J, Seikkinen A, Xia YJ. Maneuvering the surface plasmon resonance properties of silver nanostructures through shape-controlled synthesis. J Phys Chem B. 2006;110:15666-15675.

33. Mosmann T. Rapid colorimetric assay for cellular growth and survival: application to proliferation and cytotoxicity assays. J Immunol Methods. 1983;65:55-63.

34. Narayanan KB, Sakthivel N. Biological synthesis of metal nanoparticles by microbes. Adv Colloid Interface Sci. 2010;156:1-13.

35. Bansal V, Rautray D, Ahmad A, Sastry M. Biosynthesis of zirconia nanoparticles using the fungus Fusarium oxysporum. J Mater Chem. 2004; 14:3303-3305.

36. Mandal D, Bolander ME, Mukhopadhyay D, Sarkar G, Mukherjee P. The use of micro-organisms for the formation of metal nanoparticles and their application. Appl Microbiol Biotechnol. 2006;69:485-492.

37. Ramezani F, Ramezani M, Talebi S. Mechanistic aspects of biosynthesis of nanoparticles by several microbes. Nanocon. 2010;12.-14.10.

38. Krumov N, Perner-Nochla I, Order S, Gotcheva V, Angelov A, Posten C. Production of inorganic nanoparticles by micro-organisms. Chem Eng Technol. 2009;32:1026-1035.

39. Kanchana A, Devarajan S, Ayyapan SR. Green synthesis and characterization of palladium nanoparticles and its conjugates from Solanum trilobatum leaf extract. Nano-Micro Letters. 2010;2:169-176.

40. Mulvaney P. Surface plasmon spectroscopy of nanosized metal particles. Langmuir. 1996;12:788-800.

41. Shankar SS, Rai A, Ahmad A, Sastry M. Controlling the optical properties of lemongrass extract synthesized gold nanotriangles and potential application in infrared-absorbing optical coatings. Chem Mater. 2005; 17:566-572.

42. Chandran SP, Chaudhary M, Pasricha R, Ahmad A, Sastry M. Synthesis of gold nanotriangles and silver nanoparticles using Aloe vera plant extract. Biotechnol Prog. 2006;22:577-583.

43. Hao E, Kelly KL, Hupp JT, Schatz GC. Synthesis of silver nanodisks using polystyrene mesospheres as templates. J Am Chem Soc. 2002;124: 15182-15183.

44. Frens G. Controlled nucleation for the regulation of the particle size in monodispersed gold suspensions. Nat Phys Sci. 1973;241:20-22.

45. Wangoo N, Bhasin KK, Suri CR. Synthesis and capping of waterdispersed gold nanoparticles by an amino acid: bioconjugation and binding studies. J Colloid Interface Sci. 2008;323:247-254.

46. Calzolai L, Franchini F, Gilliland D, Rossi F. Protein-nanoparticle interaction: identification of the ubiquitin-gold nano-particle interaction site. Nano Lett. 2010;10:3101-3105. 


\section{Supplementary figures}

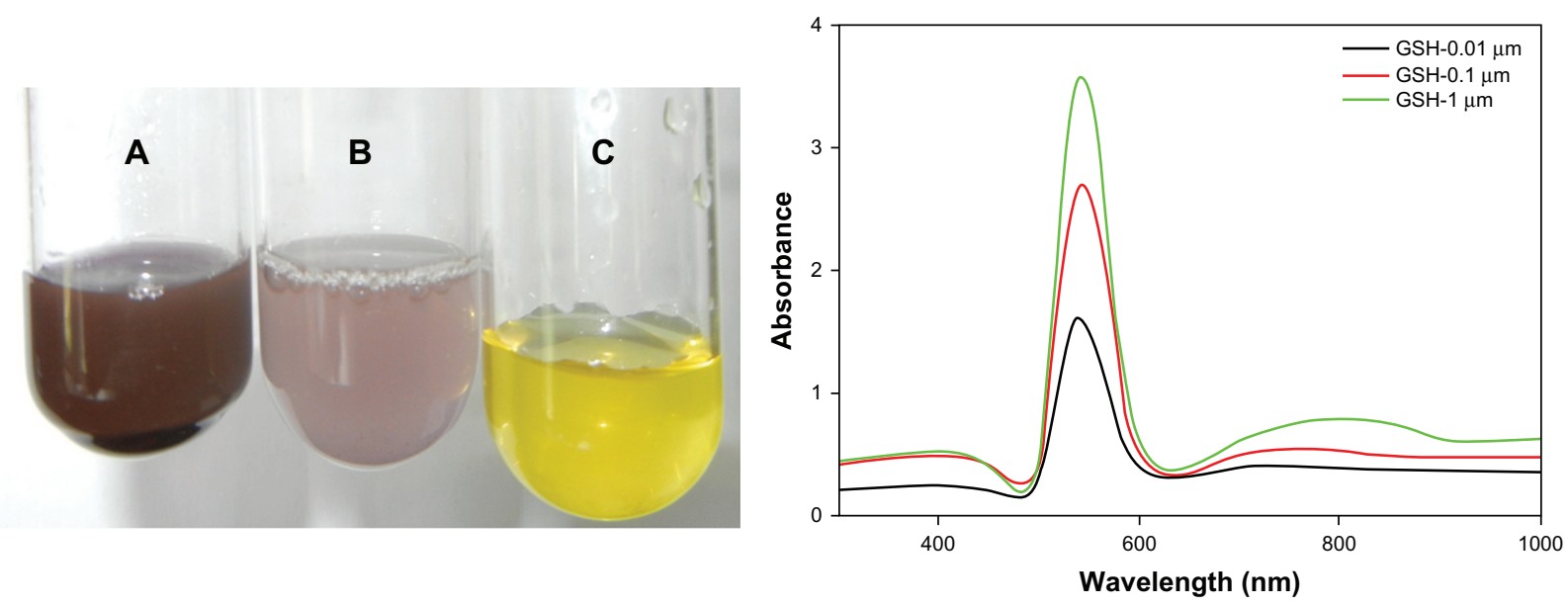

Figure SI Optical photograph depicting change in color of reaction mixture as a result of change in surface plasmon resonance upon incubation of $\mathrm{HAuCl}_{4}$ solution ( $\left.10^{-3} \mathrm{M}\right)$ with increasing amounts of dithiothreitol. Incubation of $\mathrm{HAuCl}_{4}$ with glutathione resulted in synthesis of gold nanoparticles assessed by measuring change in surface plasmon resonance.

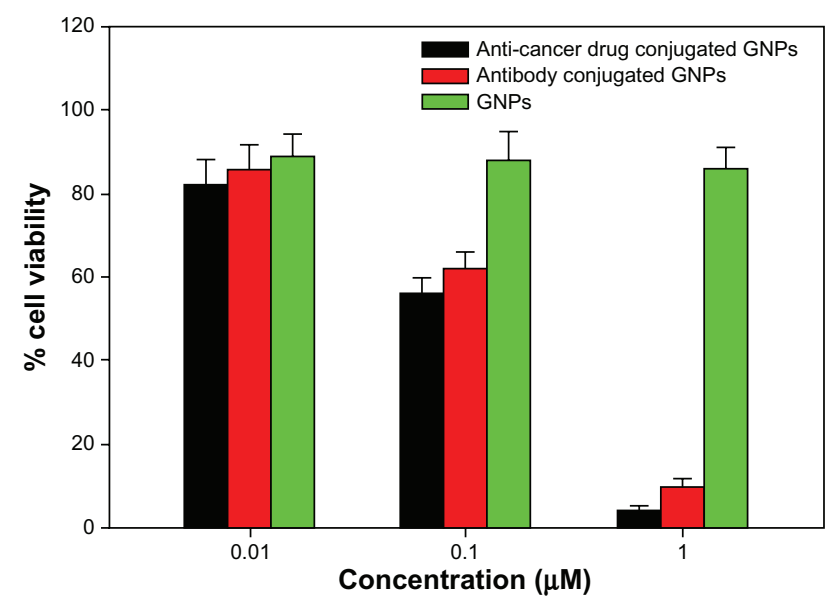

Figure S2 Graph represents differential cytotoxic effect of anticancer drug as well as antibody-conjugated gold nanoparticles against cancer cells as revealed by MTT assay. Plain gold particles were taken as control.

\section{Publish your work in this journal}

The International Journal of Nanomedicine is an international, peerreviewed journal focusing on the application of nanotechnology in diagnostics, therapeutics, and drug delivery systems throughou the biomedical field. This journal is indexed on PubMed Central,

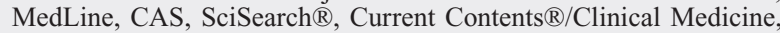

Journal Citation Reports/Science Edition, EMBase, Scopus and the Elsevier Bibliographic databases. The manuscript management system is completely online and includes a very quick and fair peer-review system, which is all easy to use. Visit http://www.dovepress.com/ testimonials.php to read real quotes from published authors.

\footnotetext{
Submit your manuscript here: http://www.dovepress.com/international-journal-of-nanomedicine-journal
} 